\title{
Optimising post- collision repair costs with the use of the audanet system with $3 d$ intelligent graphics
}

\author{
Iwo Aleksandrowicz ${ }^{1}$, Piotr Aleksandrowicz ${ }^{2 *}$ \\ ${ }^{1}$ Almot-Ekspert, Technical Department, Janusza Kusocińskiego 1, 86 032, Niemcz, Poland \\ ${ }^{2}$ Faculty of Mechanical Engineering, Department of Machine Operation and Transport, Bydgoszcz \\ University of Science and Technology, al. prof. S. Kaliskiego 7, 85 796, Bydgoszcz, Poland
}

\begin{abstract}
Transporting people and goods poses a risk of participating in road collisions which results in damage to be eliminated to bring the car back to operation. When running a business, it is essential to optimise the repair costs. Also, the insurance companies search for repair cost determination methods adequately to the damage incurred. Currently the post-collision cost calculations are supported by specialised IT tools offering various spare parts assortments to be used for repair, painting methods as well as the process of technological replacement of the elements damaged. Cars, due to their complex structure, require a new approach to the process of determining the size of damage and the resulting repair cost. The article covers the problem of optimising the post-collision repair costs while using 3D Intelligent Graphics of AudaNet. The procedures presented in the article can be used by researchers modelling technological post-collision repair processes and they are applicable.
\end{abstract}

\section{Introduction}

Since Poland entered the European Union, the post-collision car repairs, as every other business activity, have required searching for cost-cutting opportunities. Besides, for the car user and for the car repair workshop, it is essential to determine repair costs and time as well as to optimise the post-collision repair costs. The insurance companies which cover the car repair costs as part of their insurance services also search for the ways to optimise the damages paid out by applying state-of-the-art IT tools for repair cost calculation. First of all, a short calculation time facilitates verifying the repair cost items and making economic repair effects analyses. It is important for the damage liquidation process stakeholders, especially the aggrieved person, the repair workshop and for the insurance company. Currently, some support for the expert making the post-collision repair cost calculation is provided by computer programs. The analytical calculations based on catalogue publications have been completely replaced in practice. The IT systems, on the other hand, offer various spare part assortments, painting and body repair methods with real-time calculations. Currently, to build vehicles, materials as special kinds of metal sheets, cast aluminium and forged elements are

\footnotetext{
*Corresponding author: paleksandrowicz@pbs.edu.pl
} 
used. Vehicles are also equipped with electronic and active and passive safety systems if the vehicle safety is to be recovered, the right spare parts are needed. Repair cost calculation without IT tool support is today becoming impossible. Therefore, it is required from the expert to take a new approach to post-collision cost determination process. It is thus already a stage of determining the damaged car repair plan, considering also a reconstruction of the surface layer of the pieces repaired and antirust coats $[1,2,3]$. As a result, it translates into the damage size determined with an application of IT tools to calculate repair costs, adequate to the kind of damage identified.

\section{IT tools and research procedures}

To present the circumstances in which the damage was incurred, a simulation program for the road collision reconstruction, V-SIM version 4.0.34, was used. It is a program facilitating a simulation of vehicle collision with barriers on the road and between vehicles. The program can include, e.g., the vehicle load, braking, turning or accelerating. The functions were used for a simulation of the damage incurrence circumstances. Modelling engine parameter and movement vehicle as well as vehicles collision and transporting loads have been discussed in other papers $[4,5,6,7,8]$.

However, for repair cost calculations, the AudaNet program with 3D Intelligent Graphics was applied. It is a state-of-the-art Internet platform facilitating communication among the damage liquidation process participants and the repair cost calculation following the specific vehicle make manufacturer's technology and eliminating the duplication of the process operations. 3D graphics facilitates a visualisation of the vehicle parts the way they look on the car, which makes identifying parts easier. The program database includes the prices of the spare parts of the chassis, equipment option, steering, exhaust system, the suspension, engine and the gearbox. The program dialog window in the damage zone selection mode is given in Fig. 1 (https://www.audanet.pl). The program offers also two painting methods; vehicle manufacturer's and the Allianz Centre's for Technology.

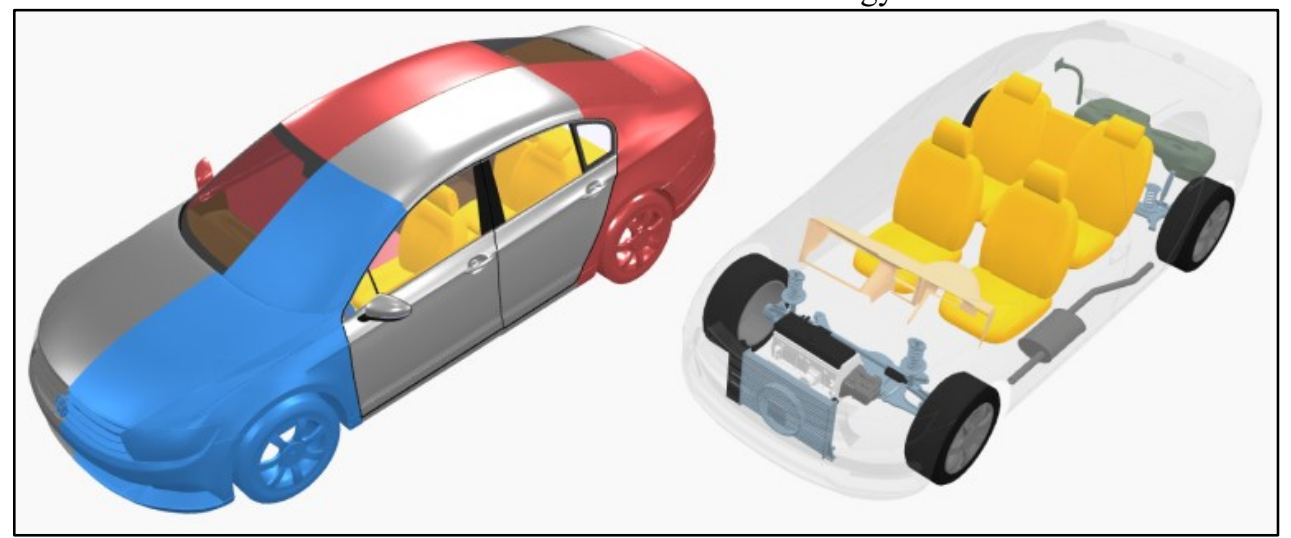

Fig. 1. AudaNet dialogue window in the damage zone selection mode.

\subsection{Vehicle damage circumstances and repair plan}

The vehicle damage circumstances involved the vehicle's front impact into a stopped preceding car. The object of the study was not observed to have activated the airbags and so, from [9], specifying the collision velocity was assumed as $20 \mathrm{~km} / \mathrm{h}$. Fig. 2 presents a collision which resulted in a damage to the front part of the body and the internal vehicle elements illustrated in the cars as the hatched area (in red). 


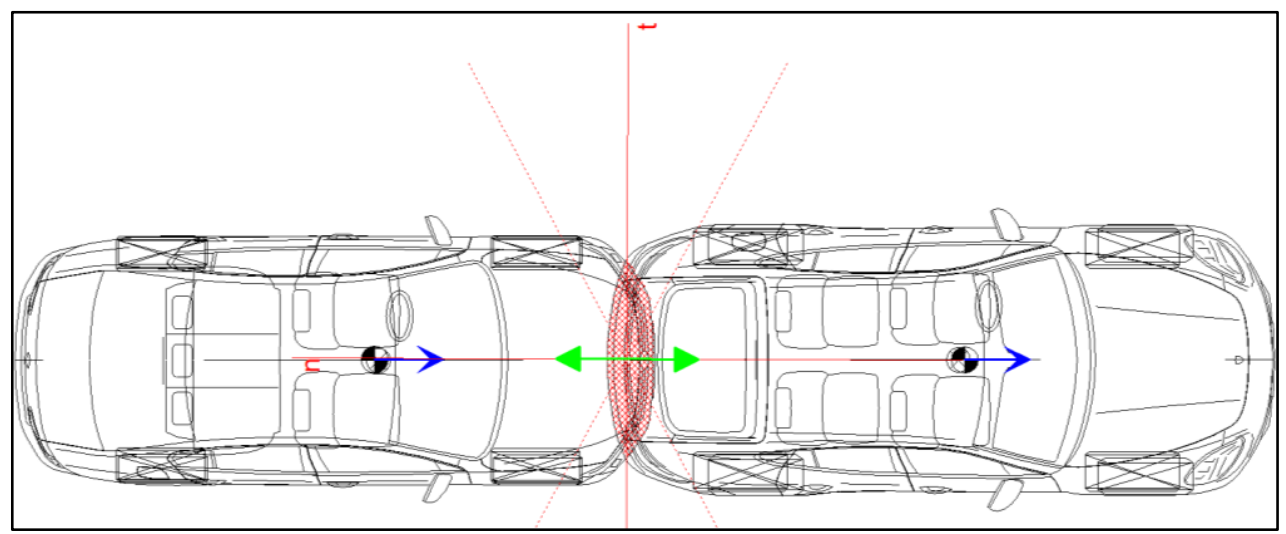

Fig. 2. Vehicle's impact into the preceding vehicle.

To develop the right vehicle repair plan, vehicle identification is required providing the following data:

- Make and model, type and Vehicle Identification Number (VIN),

- Body type, number of doors,

- Date of manufacture and the first registration date in the country and, possibly, abroad,

- Tyre type and brand and tyre condition;

- Vehicle equipment option;

- Paint coat type and condition;

- What is missing in terms of equipment option or faulty operations of systems and mechanisms.

Developing the repair plan requires the expert to diagnose the condition of the vehicle and determining which elements damaged are to be replaced and which - to be repaired. A complex vehicle construction, a variety of the materials used and the technology requirements specified by the manufacturer in terms of the specific vehicle repair call for supporting information from expert system databases to be provided. AudaNet allows for using the AudaVin program decoding the vehicle VIN number, thanks to which the expert is automatically provided with the type of the vehicle and the manufacturer's equipment option and well as the spare parts specification and repair technology.

The role of the expert in the process is of key importance. At that stage, a scope of damage and the repair method are agreed to guarantee bringing back the car to the condition as prior to the damage, also in terms of safety recovery. The procedures have been used further in the article and in variant calculations.

During the vehicle inspection and the vehicle condition diagnosis for a repair plan development to document the damage, photographs must be taken. The damage to the vehicle and its deformations must be photographed in perpendicular planes from four sides, towards the longitudinal axis and the transverse axis of the vehicle as well as, additionally, diagonally. In practice, insurance companies also require VIN number photographs and the hodometer readout as well as any vehicle damage not related to the damage in question and the defects of the previous repairs disclosed. For body damage, the authors of the article also recommend measuring the paint coat thickness with a meter each time, which is discussed, for example, in another paper [10]. 


\section{Case study; own study}

The technical data of the study object, Volkswagen Passat (3G), with the type code Audatex 06E202, is given in Table 1.

The vehicle repair plan covers the elements damaged as a result of the collision:

- Front bumper with an air-inlet grille and a spoiler; a replacement,

- Front bumper reinforcement; a replacement,

- Headlights with blinkers; a replacement,

- Fog lamps (halogen lights); a replacement,

- Air-inlet grille (front grille); a replacement,

- Front wings; a replacement,

- Engine compartment cover; a replacement,

- Radiator; a replacement,

- Air-conditioning condenser (radiator); a replacement,

- Front reinforcer; 1 manhour repair.

Table 1. Vehicle's technical condition.

\begin{tabular}{|c|c|}
\hline Make & Volkswagen \\
\hline Type/ model & Passat, Comfortline \\
\hline Registration number & XX ZZZZ \\
\hline Year of manufacture & 2015 \\
\hline First registration date & $15.05 .2015 \mathrm{r}$ \\
\hline Chassis number & WVWZZZ3CZFE123456 \\
\hline Paint type & Perlcolor \\
\hline
\end{tabular}

Fig. 3 presents the program dialogue window in the cooling and air-conditioning damage zone parts selection mode and Fig. 4 - the front external body part (https://www.audanet.pl).

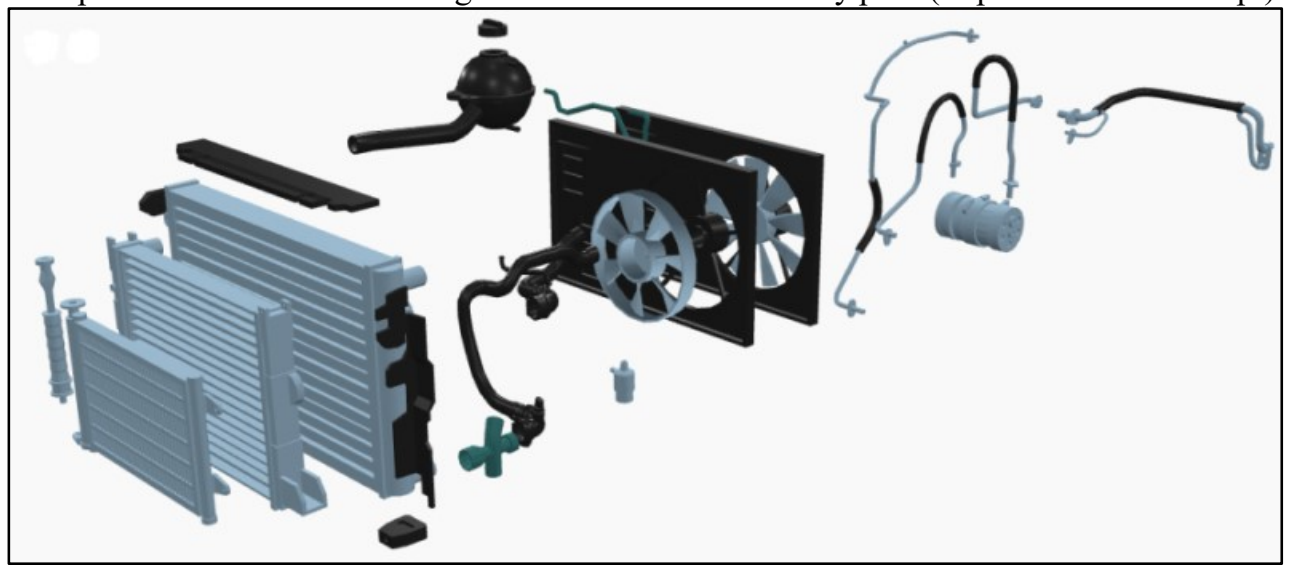

Fig. 3. Cooling and air-conditioning damage zone selection mode. 


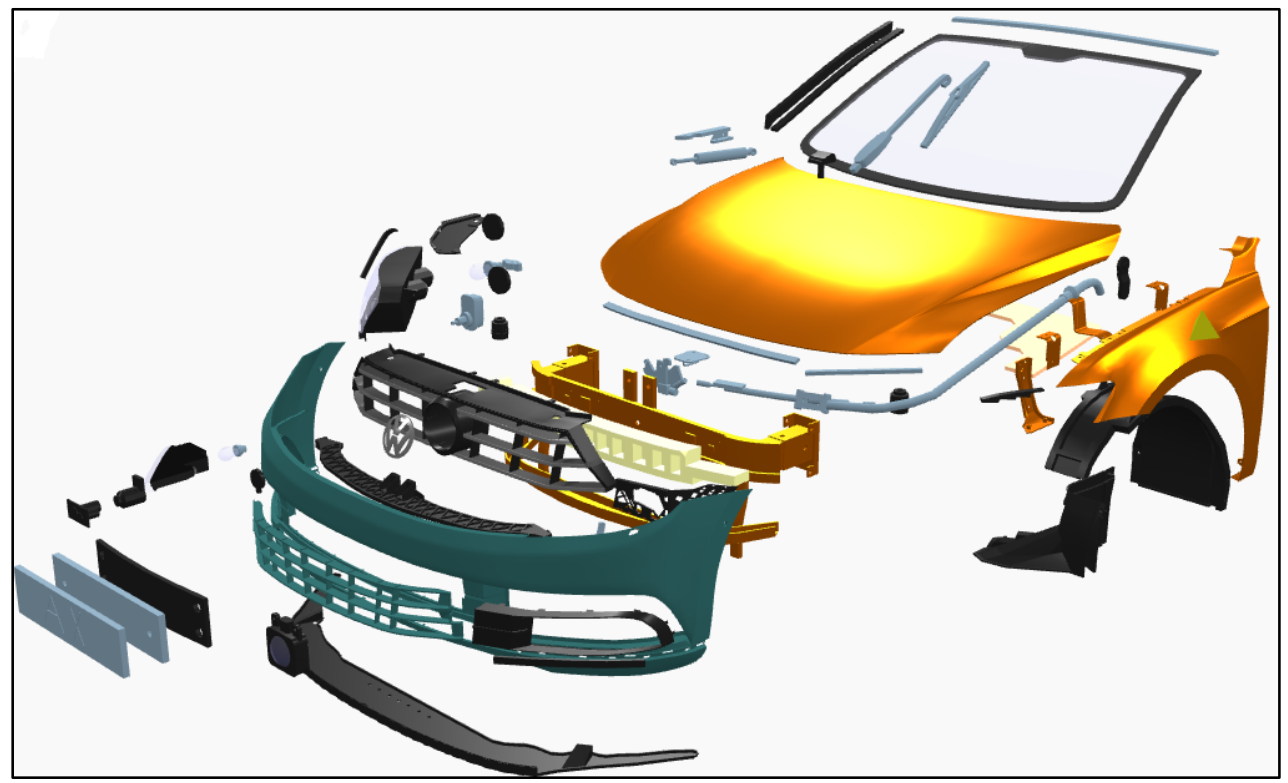

Fig. 4. Front external body part damage zone parts selection mode.

The repair costs have been calculated for the manhour rate of PLN 150 (net). The part quality classification followed the data published by Audatex (https://www.audanet.pl/audatexhelp/estimatics/pl/HTML/index.htm):

$\mathrm{O}$ - original parts with the vehicle manufacturer logo,

$\mathrm{Q}$ - original parts of the alternative supplier with the manufacturer's trademark,

$\mathrm{P}$ - parts of comparable quality.

The results of the variant calculations have been broken down in tables. Table 2 original parts type $\mathrm{O}$ with the vehicle manufacturer's logo. Table 3 original parts type $\mathrm{Q}$ from alternative suppliers. Table 4 parts of comparable quality P.

Table 2. Repair cost components original parts from the manufacturer's vehicle $\mathrm{O}$.

\begin{tabular}{|c|c|c|c|}
\hline Spare parts & & & 14710.30 PLN \\
\hline Paint material according to AZT & 119 JC & $\begin{array}{c}150,00 \\
\text { PLN }\end{array}$ & 1785.00 PLN \\
\hline Auto body technician & $17,40 \mathrm{~J}$ C & $\begin{array}{c}150,00 \\
\text { PLN }\end{array}$ & 1376,00 PLN \\
\hline Car painter & & & 294.21 PLN \\
\hline Minor and additional materials & Maintenance & $\begin{array}{c}\text { Total repair costs } \\
\text { (net) }\end{array}$ & 20605.53 PLN \\
\hline & \multicolumn{3}{|c|}{$\begin{array}{c}\text { Total repair costs } \\
\text { (gross) }\end{array}$} \\
\hline
\end{tabular}


Table 3. Repair costs components original parts of alternative suppliers Q.

\begin{tabular}{|c|c|c|c|}
\hline Spare parts & & 11357.58 PLN & 2320.02 PLN \\
\hline Paint material according to AZT & 119 JC & $\begin{array}{c}150,00 \\
\text { PLN }\end{array}$ & 1785.00 PLN \\
\hline Auto body technician & $17,40 \mathrm{~J}$ C & $\begin{array}{c}150,00 \\
\text { PLN }\end{array}$ & 1376,00 PLN \\
\hline Car painter & & 227.15 PLN & 120.00 PLN \\
\hline Minor and additional materials & & & 17185.75 PLN \\
\hline Maintenance & Total repair cost \\
(net) & Total repair cost \\
(gross) & 21138,47 PLN \\
\hline & \multicolumn{2}{|c|}{} \\
\hline
\end{tabular}

Table 4. Repair cost components parts of comparable quality P.

\begin{tabular}{|c|c|c|c|}
\hline Spare parts & & 5418.28 PLN & 2320.02 PLN \\
\hline Paint material according to AZT & 119 JC & $\begin{array}{c}150,00 \\
\text { PLN }\end{array}$ & 1785.00 PLN \\
\hline Auto body technician & $17,40 \mathrm{~J}$ C & $\begin{array}{c}150,00 \\
\text { PLN }\end{array}$ & 1376,00 PLN \\
\hline Car painter & & 108.37 PLN & 120.00 PLN \\
\hline Minor and additional materials & Maintenance & $\begin{array}{c}\text { Total repair costs } \\
\text { (net) }\end{array}$ & 11127.67 PLN \\
\hline & \multicolumn{2}{|c|}{$\begin{array}{c}\text { Total repair costs } \\
\text { (gross) }\end{array}$} & 13687,03 PLN \\
\hline & \multicolumn{2}{|c|}{} \\
\hline
\end{tabular}

Figs 5-7 provide a breakdown of the repair cost for the above three variants and Fig. 8 - a comparison of the total costs across the repair cost calculation variants. The calculations show that the repair costs are dominantly affected by the evaluation of spare parts used for post-collision vehicle repair effect on repair costs. The costs of original spare parts from alternative suppliers are $23 \%$ lower than the original spare parts with the vehicle manufacturer's logo. The costs of spare parts of comparable quality, however, are $63 \%$ lower than the original ones with the vehicle manufacturer's logo. 


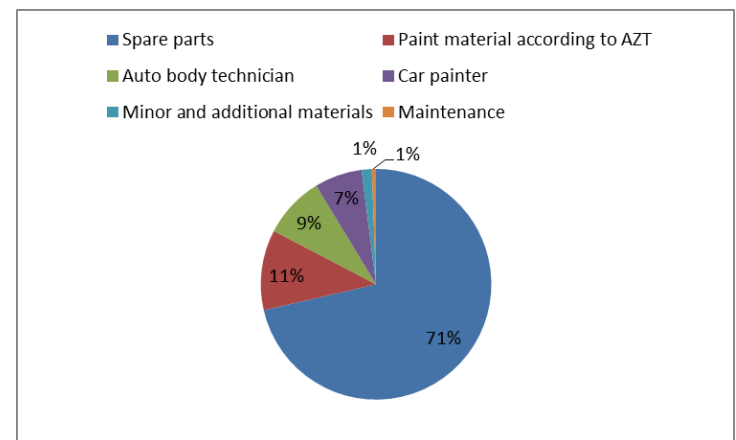

Fig. 5. Repair cost components vehicle manufacturer's original parts $O$.

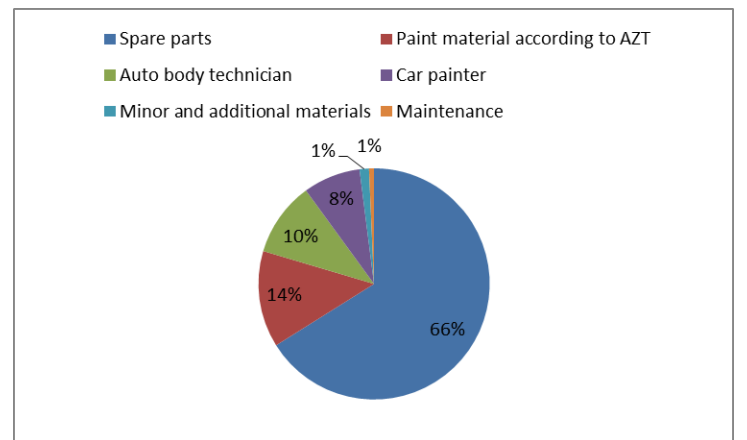

Fig. 6. Repair cost components original parts from alternative suppliers Q.

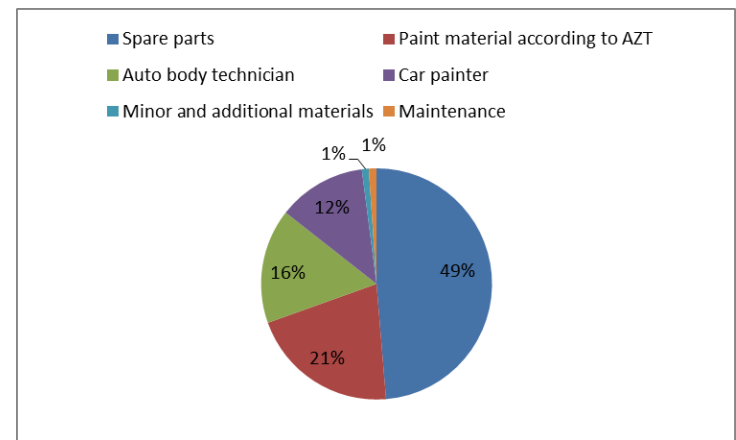

Fig. 7. Repair cost components parts of comparable quality $P$.

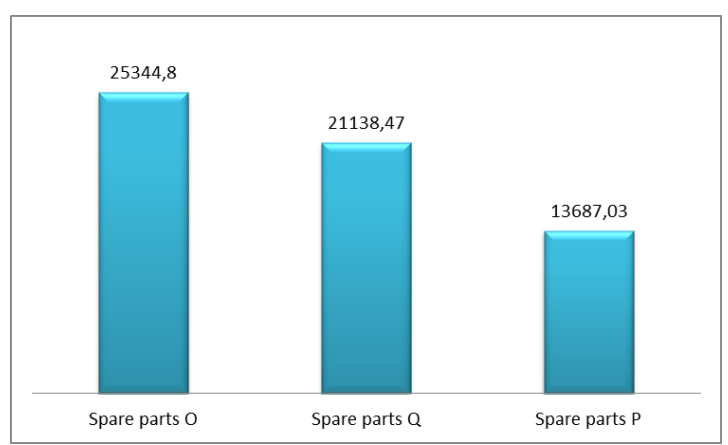

Fig. 8. Total repair cost comparison parts: $O, Q$ and $P$. 


\section{Conclusions}

The analysis leads to the following conclusions:

- The dominant post-collision repair cost is generated by the spare part prices; the higher the quality of the spare parts used for repair, the higher the effect on the total post-collision repair cost,

- The cost of bodywork and painting labour and paints irrespective of the type of the spare parts used for vehicle repair remain unchanged and other methods to cut down on repair costs in terms of vehicle bodywork and painting must be searched for,

- A possibility of optimising repair costs has been confirmed by applying various kinds of spare parts, however, as recommended by the authors, identifying the type of the spare parts damaged in the vehicle to avoid court litigation to ensure bringing the vehicle back to the state as prior to the damage by using the spare parts not assembled when the damage occurred.

\section{References}

1. T. Seidel. Car body repair technology. Technotrasfer (2014)

2. M. Blicharski. Surface engineering. Polish Scientific Publishers PWN (2021)

3. G. Boruta, A. Piętak. Car mechatronics. Active and passive safety systems. Publishing University of Warmia and Mazury (2012)

4. P. Kučera, V. Píštěk, A. Prokop, K. Řehák. Measurement of the powertrain torque, in Proceedings of the $24^{\text {th }}$ International Engineering Mechanics 2018, 14-17.05.2018 Svratka, Czech Republic, pp. 449-452, (2018)

5. V. Píštěk, L. Klimeš, L. Mauder, P. Kučera. Optimal design of structure in rheological models: an automotive application to dampers with high viscosity silicone fluids. Journal of Vibroengineering 19, 6 (2017)

6. O. Fomin, A. Lovska, V. Píštěk, P. Kučera. Research of stability of containers in the combined trains during transportation by railroad ferry. MM Science Journal 1 (2020)

7. M. Markiewicz, Ł. Muślewski, M. Pająk. Impact biocomponent additive to diesel oil on values of selected functional parameters of transport means. Polish Journal of environmental studies, 29, 5 (2020)

8. M. Markiewicz, Ł. Muślewski. The impact of powering an engine with fuels from reneweble energy sources inclouding its softwere modification on a drive unit performance parameters. Sustainaibility 11, 23 (2019)

9. P. Aleksandrowicz, I. Aleksandrowicz. Verification of the conditions for Whiplash-type injuries with the SDC method using the SRS-AIRBAG system activation parameters. Transport problems 154.2 (2020)

10. J. Gonera, R. Michalski. Comprehensive assessment of the technical condition of the car body. BEL Studio 2 (2011) 